Final submitted version of paper subsequently published as: Cotton, D.R.E., Morrison, D., Magne, P., Payne, S. and Heffernan, T. (2018) Global Citizenship and Cross-cultural Competency: Student and expert understandings of internationalisation terminology. Journal of Studies in International Education.

\title{
Global Citizenship and Cross-Cultural Competency: Student and expert understandings of internationalisation terminology
}

\author{
Debby R.E. Cotton*, David Morrison*, Polly Magne*, Simon Payne*, Troy Heffernan\# \\ Date of submission: $9^{\text {th }}$ March 2018 \\ * University of Plymouth, Plymouth, UK \\ \#University of Wollongong, Wollongong, Australia
}

Corresponding author:

Dr Troy Heffernan

School of Management, Operations and Marketing

Faculty of Business

University of Wollongong

NSW 2522

Australia

$\mathrm{T}+61$ (0) 242215437

E-mail: troyh@uwa.edu.au

\section{Biographies:}

Professor Debby Cotton is Head of Educational Development in the Pedagogic Research Institute and Observatory (PedRIO), University of Plymouth, UK. She has a doctorate in education from Oxford University, and has published more than 70 papers on a wide range of HE teaching and learning issues including sustainability education, research-informed teaching, internationalisation of higher education, and inclusivity. You can find out more about Debby's work and publications here:

https://www.plymouth.ac.uk/staff/debby-cotton

ORCID ID: D.R.E Cotton http://orcid.org/0000-0001-7675-8211

Dr David Morrison is a Research Assistant in the Pedagogic Research Institute and Observatory (PedRIO), University of Plymouth, UK. His research and teaching interests cover a range of Higher Education topics including developing effective interdisciplinary education, internationalisation of the curriculum, e-learning and digital learning environments, evaluation of higher education quality, and historiography.

ORCID ID: Dave Morrison http://orcid.org/0000-0002-5558-4483

Ms Polly Magne is an Educational Developer and the Programme Director for the Postgraduate Certificate in Academic Practice at the University of Plymouth, UK. With more than 20 years of experience teaching across the primary, secondary and Higher Education sector, Polly has developed expertise in curriculum and assessment design, dynamic teaching approaches, and inclusive classroom facilitation. Her research publications include themes such as: inclusive assessment; effective feedback; 
Final submitted version of paper subsequently published as: Cotton, D.R.E., Morrison, D., Magne, P., Payne, S. and Heffernan, T. (2018) Global Citizenship and Cross-cultural Competency: Student and expert understandings of internationalisation terminology. Journal of Studies in International Education.

and internationalisation of Higher Education. You can find out more at https://www.plymouth.ac.uk/staff/pollyanna-magne

Professor Simon Payne is Deputy Vice Chancellor (International and Planning), University of Plymouth, UK. He has a professional and academic law career spanning over 30 years and has held key senior leadership roles including Head of the School of Law, Associate Dean (International), Acting Dean of Business and Dean of Academic Partnerships. He leads international developments at the university of Plymouth, and his research covers a range of areas including international environmental law.

Dr Troy Heffernan is Marketing Discipline Group Leader in the Faculty of Business, University of Wollongong, Australia. He is a Senior Fellow of the HEA (UK) and Wollongong Academy of Tertiary Teaching \& Learning Excellence (Aus). Troy has published extensively in the field of International Education, primarily around Transnational Education, and has spoken on this subject around the globe for the British Council and other organisations. Prior to his position at UOW, Troy was Professor of Transnational Education and Director of the International Centre at Plymouth University, UK. You can find out more about Troy's work and publications here:

https://scholars.uow.edu.au/display/troy heffernan

ORCID ID: Troy Heffernan http://orcid.org/0000-0003-4558-7709 
Final submitted version of paper subsequently published as: Cotton, D.R.E., Morrison, D., Magne, P., Payne, S. and Heffernan, T. (2018) Global Citizenship and Cross-cultural Competency: Student and expert understandings of internationalisation terminology. Journal of Studies in International Education.

\section{Abstract}

Internationalisation of the curriculum is of increasing interest in many universities, yet the terminology used to describe it is highly varied and it is not clear that students understand its core concepts. This study explores students' understandings of the terms global citizenship and cross-cultural competency, and compares them with use in the literature and by experts. A large-scale questionnaire of students from a range of disciplines is supplemented with qualitative data from pedagogic and internationalisation experts. Findings indicate that student understandings of both terms were mixed, and frequently differed from the way the terms are used by experts and in the literature. The concept of cross-cultural competency was more likely to invoke a sense of agency amongst students than was global citizenship, contrary to how they are depicted in the literature. This suggests that there may be some pedagogic benefits to be gained from using the former term.

\section{Keywords}

Internationalisation of higher education; Internationalisation of the curriculum; global citizenship; crosscultural competency; agency

\section{Introduction}

Increasing globalisation and demands from employers for globally prepared graduates has had a significant impact on higher education (HE). As concern for student employability has grown, so too has interest in internationalisation of the curriculum $(\mathrm{loC})$ - focusing on the experience of home students, primarily in the formal curriculum, in addition to universities' long-standing efforts to attract international students (see Leask 2015). We use the term loC in this paper, rather than the related 'Internationalisation at Home' (laH) to indicate the focus of this study on the taught curriculum in a domestic context, rather than including wider issues such as internationalisation of the campus. Importantly, internationalisation of the curriculum does not require international students to be present in the classroom - or for domestic students to undertake overseas experiences (Beelen and Jones, 2015) - which makes it of relevance in a wide range of institutional contexts.

loC has been widely discussed in the literature, with considerable debate concerning its intended outcomes. Some authors (e.g. Knight, 2006; Beelen and Leask, 2011) argue that loC aims to help students develop international understanding and intercultural skills or competencies. Others claim that it helps develop students' employability and transferable skills (Crossman and Clarke 2010; Beelen and 
Final submitted version of paper subsequently published as: Cotton, D.R.E., Morrison, D., Magne, P., Payne, S. and Heffernan, T. (2018) Global Citizenship and Cross-cultural Competency: Student and expert understandings of internationalisation terminology. Journal of Studies in International Education.

Jones, 2015). Underpinning much of the loC literature is the idea that students will be encouraged to take personal responsibility for engagement with international communities if they make linkages with international elements of their discipline (e.g. Jones and Killick 2013, UNESCO 2015). Diverse perceptions of the aims of $\mathrm{IOC}$, combined with a lack of clarity on what many of the terms mean to different stakeholders, may explain reported differences in the literature as to whether aspirational outcomes are achieved (Hanson, 2010; Rhoads and Szelényi 2011; Jones and Killick 2013).

In this paper we explore students' understandings of two of the most frequently used terms used in loC - Global Citizenship (GC) and Cross-Cultural Competency (CCC). We compare student understandings to the use of these terms in the literature and by experts, and consider implications for internationalising the curriculum. Unlike much previous research which has focused on business disciplines, we explore students' views in diverse subjects.

\section{Terminology}

The loC literature invokes a fairly consistent set of key terms, such as global citizenship, cross-cultural competency, multiculturalism, and cultural awareness. Global Citizenship appears most frequently in academic literature, as well as in policy statements (e.g. UNESCO 2015; OXFAM 2017). A brief review of 114 UK university strategies in 2015 as part of the preparation for this project showed 'global citizenship' mentioned in 94 of them. Cross-cultural competency appears less widely, and seldom in policy documents. Nevertheless, in a review of 399 journal abstracts on loC from 2010 to 2015, the term was prominent in subject-specific literature - especially Business literature, which accounted for $41 \%$ of the total papers. Before reporting our research, we will summarise the ways in which these terms have been handled in the literature.

\section{Global Citizenship}

At its core, there is general agreement on what Global Citizenship (GC) means:

Global citizenship refers to a sense of belonging to a broader community and common humanity. It emphasises political, economic, social and cultural interdependency and interconnectedness between the local, the national and the global (UNESCO 2015, 14). 
Final submitted version of paper subsequently published as: Cotton, D.R.E., Morrison, D., Magne, P., Payne, S. and Heffernan, T. (2018) Global Citizenship and Cross-cultural Competency: Student and expert understandings of internationalisation terminology. Journal of Studies in International Education.

However, probe beneath the surface of this apparent agreement, and there exists a proliferation of approaches, intended outcomes and subtle terminological distinctions. Some authors (e.g. Dei, 2008) see social justice as one of the key principles of GC; for others it aims to equip students for global business activities (Lilley et al., 2014). Intended outcomes range from the instrumental (e.g. open borders for employment), through the transformational (e.g. developing a personally expanded worldview) to the radical (e.g. global government or removal of nationalities) (Shultz 2007; Killick 2012; Lilley et al., 2014). This ambiguity is expressed forcibly by Oxley and Morris (2013), who note that:

"In a recent seminar series, different speakers used Global Citizenship (GC) as a basis for: justifying a ban in western society on face-covering veils for women; promoting and working with differences across cultural and religious divides; deconstructing western hegemony; and giving citizens new skills enabling them to resolve conflicts and contest injustices." (p. 301)

In an attempt to gain clarity, Morais and Ogden (2011) developed a three-dimensional Global Citizenship Scale encompassing social responsibility, global competence, and global civic engagement. According to this model, CCC appears to be situated as a sub-set of GC and one which includes knowledge and skills, but less active engagement than the broader GC concept. With similar intent, Oxley and Morris (2013) offer a wide-ranging review of different approaches to GC and explore the range of meanings attributed to citizenship which underlie some of the ambiguity of GC. Some argue that global citizenship is an oxymoron in the absence of a 'world government', while others argue that it is "a deep commitment to a broader moral purpose" (Oxley and Morris, p. 303). Oxley and Morris identify three distinct approaches to writing about GC, namely those that take a dichotomous approach (e.g. strong-weak or soft-critical conceptions of GC); attributes-based models (those that emphasise desirable outcomes such as responsibility, empathy etc), and the ideological ("GC-isms", p. 304), either normative or empiricallyderived. In some (but not all) of these approaches, CCC again appears as a sub-set of GC.

A common understanding of GC, though not always made explicit, is that it involves agency and active responsibility in contributing to the global community (Toh, 1996; Clifford and Montgomery, 2011; Jones and Killick, 2013; Morais and Ogden, 2011). Jones and DeWit $(2012,41)$, refer to the University of Sydney strategy which defines Global Citizens as '[graduates] who will aspire to contribute to society in a full and meaningful way through their roles as members of local, national and global communities.' The UK government's internationalisation strategy for schools (2004) also refers to GC in terms of '... the ways in which we all, as global citizens, can influence and shape the changes in the global economy, 
Final submitted version of paper subsequently published as: Cotton, D.R.E., Morrison, D., Magne, P., Payne, S. and Heffernan, T. (2018) Global Citizenship and Cross-cultural Competency: Student and expert understandings of internationalisation terminology. Journal of Studies in International Education.

environment and society.' The Morais and Ogden model includes examples such as making an impact for a chosen cause, and joining organisations and student clubs, and incorporates global civic engagement more widely as a strong dimension of GC. The high importance placed on active engagement and personal responsibility in academic literature and policy is clear.

There is considerable critique of GC in the literature, however. Some have suggested it may be a new form of colonialism, promoting Western ideals of globalism under the auspices of harmony (Pashby 2011). Hamdon and Jorgenson (2009) describe GC as a neo-liberal discourse of privileged individualism, mobility and competition. Bates (2012) suggests that global citizenship is highly elite, rhetorically appearing to be bestowed automatically on all peoples, while downplaying the marginalisation that many experience. Variations in what GC means in other cultural bases than the West have been raised by several scholars (e.g. Wang 2013; Clifford and Montgomery 2011).

What is most often unclear in the literature, however, is whether explicit attempts to embed GC in the curriculum lead to desired outcomes. It has been claimed that 'education abroad' experiences are of central importance in developing global citizenship (Morais and Ogden, 2011), yet such opportunities will only ever be accessible to a select, mostly affluent, group of university students. Several studies have failed to find any evidence of achievement of GC outcomes in students (Rhoads and Szelényi 2011; Jones and Killick 2013). In contrast, Hanson (2010) found significant increases in self-reported global responsibility, local and global aid and activism over a six-year study of GC in graduates. However, this research only included Health students on a specialised study abroad course, so it is not clear that it can be generalised.

\section{Cross-Cultural Competence}

Although mentioned throughout the literature on loC, papers dealing specifically with the term, CrossCultural Competence (CCC) are rarely found outside of subject-specific studies - most often Business and Health/Medicine. Nonetheless, there is some literature regarding the definition of CCC and related terms such as intercultural competence, global competence and cross-cultural capability. Differences between these terms are not consistent within the literature, thus in the discussion below we use whichever term was employed by the author cited.

Gersten (1990) originally defined CCC as an individual's ability to function effectively in another culture, and similar definitions are widely used in the literature. Hunter et al. (2006) use the term 'global 
Final submitted version of paper subsequently published as: Cotton, D.R.E., Morrison, D., Magne, P., Payne, S. and Heffernan, T. (2018) Global Citizenship and Cross-cultural Competency: Student and expert understandings of internationalisation terminology. Journal of Studies in International Education.

competence', but the definition appears very similar to CCC, albeit more detailed: "having an open mind while actively seeking to understand cultural norms and expectations of others, leveraging this gained knowledge to interact, communicate and work effectively outside one's environment" (p. 277). Bird et al. (2010) attempt to identify specific dimensions of what they call 'intercultural competence', in the context of global leadership. They identify three dimensions: perception management, relationship management and self management. Perception management concerns the ways in which individuals approach cultural difference, and includes having a non-judgemental attitude, being inquisitive, and tolerating ambiguity. Relationship management encompasses the ways in which an individual interacts with others and builds relationships. It includes emotional sensitivity, self-awareness and social flexibility. Self management is related to an individuals' ability to handle stressful situations and manage emotions. It includes optimism, self-confidence and emotional resilience. These elements seem to provide a strong underpinning for understanding the varied facets of CCC.

An important debate in the context of education has arisen around the issue of whether CCC is intrinsic or can be learned. Leiba-O'Sullivan (1999) proposed 'stable' and 'dynamic' versions of CCC, with 'stable' incorporating personality traits and intrinsic interest, and 'dynamic' entailing learned skills and knowledge. Johnson et al. (2006), however, claimed that personality traits are not part of CCC at all, but merely pre-conditions. They define $\mathrm{CCC}$ as a set of skills and practices which can be taught:

....an individual's effectiveness in drawing upon a set of knowledge, skills, and personal attributes in order to work successfully with people from different national and cultural backgrounds at home or abroad (Johnson et al. 2006, 530).

Caligiuri and Tarique (2012), using a sample of 420 global leaders, found that both personality traits and experience were influential in predicting a leader's level of cross-cultural competency (including tolerance of ambiguity, cultural flexibility, and reduced ethnocentrism). This would suggest that at least some aspects of CCC can be enhanced through experiential learning opportunities.

In contrast to GC, in definitions of CCC a sense of agency is largely absent, the focus tending to be more on instrumental elements such as the ability to communicate or work across cultures. Discussions about teaching CCC have similarly focused on instrumental features: Early (2002) addressed motivational factors in developing CCC in students, noting that engagement is unlikely unless the approach appeared 
Final submitted version of paper subsequently published as: Cotton, D.R.E., Morrison, D., Magne, P., Payne, S. and Heffernan, T. (2018) Global Citizenship and Cross-cultural Competency: Student and expert understandings of internationalisation terminology. Journal of Studies in International Education.

relevant and useful. Jones (2013) called for more efforts to show students the positive impact of internationalisation on employability. Nonetheless, some definitions of CCC touch on similar ideas to GC, and there is undoubtedly some overlap between the way the terms are used in the literature.

Only one study was identified which explicitly asked students what they thought either of these terms meant. Odag et al. (2016) asked first-year students at a German university to define 'intercultural competence' (considered to be analogous to CCC). They found that students mostly defined it as awareness, tolerance and understanding of other cultures, contrary to the instrumental definitions above. However, this study did not explore student understandings of other terms, and the questions were asked after undertaking targeted training, making the results difficult to generalise.

This review of the literature and terminology has identified some gaps, particularly around student understanding of key terms. Our research was designed to explore student understandings of GC and CCC across a range of subjects prior to undertaking any specialist courses. Thus we offer a student perspective which is more robust and generalizable than some of the earlier research on targeted groups. To provide a deeper understanding, we also explore the views of pedagogic and loC experts, and conclude with a discussion of the implications for effective pedagogies for loC.

\section{Methodology}

The aim of this research was to explore stakeholder understandings of GC and CCC to determine any patterns in responses and relationship to definitions in the literature. This research forms part of a larger project which evaluated the impact of small scale changes to the curriculum on students' beliefs and attitudes towards loC. However, this survey was undertaken before any intervention occurred. Research questions for this phase included:

- What are students' and experts' understandings of the terms global citizenship and crosscultural competency?

- What are the similarities and differences between their reported understandings and those discussed in the literature and policy documents?

- What are the implications of the findings for development of loC across a range of disciplines?

The methods for collecting students' and experts' perspectives are described in more detail below.

\section{Student views}


Final submitted version of paper subsequently published as: Cotton, D.R.E., Morrison, D., Magne, P., Payne, S. and Heffernan, T. (2018) Global Citizenship and Cross-cultural Competency: Student and expert understandings of internationalisation terminology. Journal of Studies in International Education.

First-year undergraduate students in selected courses were surveyed across nine subjects spanning four faculties at a major UK university (see table 1).

Table 1 about here

A purposive sampling approach (Bryman 2008) was taken to ensure:

- Representation of all students in a subject

- Representation of a range of subjects and faculties

- Inclusion of students who had just commenced study, rather than those who might have experienced targeted loC efforts

Surveys were administered to students during class in the fourth week of their first term. This approach avoided problems of self-selection and low response rates often faced by online surveys (Ilieva et al., 2002). Critically, it elicited the views of students who may see internationalisation as irrelevant to them or their subject, and may not complete an online survey. A total of 494 valid surveys were collected. Class sizes varied but response rates were generally high (see table 2).

\section{Table 2 about here}

In this paper, we focus on student responses to the two open-ended questions below:

- Please describe what 'global citizenship' means to you.

- Please describe what 'cultural competence' or 'cross-cultural competency' means to you.

Students were not required to provide a response to these (or any) questions, though just over two thirds answered each question.

Responses were analysed using the constant comparative method to draw out cross-cutting themes (Silverman, 2005), a process of reading and re-reading data, looking for similarities and differences between accounts, and specific references denoting agency or responsibility. We followed an iterative process of refining codes until we were confident that the categories were clearly distinct (or hierarchically related). We took particular care with coding of students' expressions of agency and responsibility. We identified a distinction between responses that mentioned having a particular skill or being a particular way, and responses that mentioned doing a thing or acting on something. In nearly all 
Final submitted version of paper subsequently published as: Cotton, D.R.E., Morrison, D., Magne, P., Payne, S. and Heffernan, T. (2018) Global Citizenship and Cross-cultural Competency: Student and expert understandings of internationalisation terminology. Journal of Studies in International Education.

cases where one type was present, the other was not. These were coded as 'inactive agency' and 'active agency' respectively.

\section{Expert views}

To supplement the students' views, we explored how expert academics understood GC and CCC, working with a small sample using a modified Delphi technique. We identified academic experts on loC, as well as a group of National Teaching Fellows (NTFs) ${ }^{1}$, pedagogic experts in the same subjects as the students. The Delphi Technique involves an 'iteration of anonymous questionnaire responses to achieve consensus by an expert panel' aimed at producing 'a detailed critical examination and discussion' of a particular topic or issue (Green, 2014, 6). Our study involved two rounds of questions, and took a qualitative approach. Perhaps unsurprisingly, it proved impossible to achieve complete consensus between the expert panelists; however, their responses provide a useful additional perspective.

IoC experts were selected on the basis of publication and citation records. Of the 30 experts approached five agreed to participate; these were among the most prolific and highly cited authors in the field. NTFs were selected from the Higher Education Academy's list of awards. We contacted NTFs from each of the subjects in our study and four agreed to participate, representing Mathematics, Education, Computing and Social Work.

In line with the traditional Delphi technique, each participant was emailed a set of five short answer questions to complete. These were then analysed, and a second set was circulated based on initial responses. Five of the original nine respondents completed the second set of questions, two loC experts and four NTFs. Although this is rather a limited sample, the findings add an extra dimension to the student surveys; we report them here with a note of caution regarding wider applicability.

Of the five questions asked, this paper focuses on replies to the following: 'How would you define CrossCultural Competence?' and 'How would you define Global Citizenship?' from the first round, and the follow-up question 'In the first round, responses to the terms Global Citizenship and Cross-Cultural Competence were varied, but several brought up concerns with the unreliability or ambiguity of these

\footnotetext{
1 National Teaching Fellowships are annual awards in the UK given to HE instructors in any field who distinguish themselves in teaching.
} 
Final submitted version of paper subsequently published as: Cotton, D.R.E., Morrison, D., Magne, P., Payne, S. and Heffernan, T. (2018) Global Citizenship and Cross-cultural Competency: Student and expert understandings of internationalisation terminology. Journal of Studies in International Education.

and other terms in the literature. Do you believe the term(s) we use to present internationalisation to students matter? Why, or why not, and to what degree?'

\section{Limitations}

The sampling approach utilised offers a novel perspective to that seen in much of the literature, in terms of inclusion of students from a wide range of subjects before any explicit internationalisation input, as well as including consideration of experts' views via the modified Delphi approach. However, the wideranging student sample is drawn from a single institution and, although nationally-focused, a relatively small sample of experts is involved. Whilst statistical generalisation is not possible from this sample, generalisation based on 'theoretical inference' (Hammersley, 1998) is used to theorise about the possible wider applicability of the findings. The dearth of literature which goes beyond the business disciplines, or includes triangulation of findings means that this research offers an original contribution.

\section{Findings}

\section{Student responses}

A diverse range of student responses to the question on global citizenship were received. However, it is possible to draw out some shared understandings which were widely held. Almost $50 \%$ of students referred to a global community or a one-world state, consistent with definitions in the literature (see Table 3).

Table 3 about here

Despite this apparently widespread agreement, a large number of responses were paraphrases or direct re-statement of the term itself, with no qualifying addition (e.g. 'being a citizen of the world', 'a global community', 'being a citizen globally'). It is unclear whether the term was genuinely understood in many of these cases. There were a few more nuanced responses that exemplified global community (e.g. 'the idea that, above all, we are not divided by national boundaries and have the same needs.'); however these accounted for only one-quarter of the total 'global community' responses. No other category was referred to by more than $20 \%$ of students, and responses did not cluster in particular subjects. Indeed students appeared to have a wide and sometimes contradictory notion of what GC meant. 
Final submitted version of paper subsequently published as: Cotton, D.R.E., Morrison, D., Magne, P., Payne, S. and Heffernan, T. (2018) Global Citizenship and Cross-cultural Competency: Student and expert understandings of internationalisation terminology. Journal of Studies in International Education.

Fewer than a third of respondents (31.1\%) referred to GC in terms of agency, either active or inactive. Moreover, there was a sense of 'otherness' in some of the responses: while many of the responses seemed to encompass a self-inclusive principle of everyone living and working together, it was unclear from the answers that many students had a sense of responsibility or agency towards achieving this. Indeed, many students explicitly referred to being accepted elsewhere by others, but did not mention accepting others themselves. Indeed, while approximately half of the students identified the common 'core' definition of global citizenship (the broad notion of a global community), scarcely more than $10 \%$ had any sense of the moral and ethical responsibility element that dominates the GC literature.

Students' responses to the question on Cross-cultural competency were also diverse but featured one crucial difference. As in GC, the major response was one which was strongly implied by the term itself ('cultural awareness and understanding'), and there were a wide range of alternative interpretations offered. However, in this case, nearly $80 \%$ of respondents defined CCC in terms of agency, and more than a third referred to taking active personal agency in some way (see table 4). There was also a fairly high degree of uniformity in wording, even across subjects, and definitions of CCC clustered around relatively few elements. Many included most or all of the same key features into one definition (e.g. 'accepting other peoples' cultures and respecting them').

\section{Table 4 about here}

Several of the responses for CCC explicitly mentioned the need for loC or referred to shared learning between cultures. Although a slightly higher proportion of these responses came from Education, there were comments of this nature across all of the subjects. Comparatively, very few GC responses mentioned shared learning, and none referred to GC in terms of the HE curriculum. Thus, despite diverse understandings of both terms, students were more than three times as likely to interpret CCC than GC as requiring a sense of personal agency or responsibility, and more likely to identify it as something which can be learned.

\section{Expert Views}

The Delphi approach revealed varied understandings of both terms between pedagogic experts (NTFs) and internationalisation experts, and between experts and students. Perhaps unsurprisingly, given their contributions to it, the internationalisation experts had understandings which were closely aligned with 
Final submitted version of paper subsequently published as: Cotton, D.R.E., Morrison, D., Magne, P., Payne, S. and Heffernan, T. (2018) Global Citizenship and Cross-cultural Competency: Student and expert understandings of internationalisation terminology. Journal of Studies in International Education.

those in the published literature. Discussing Global Citizenship, four of the five loC experts explicitly talked about the need for students to develop personal responsibility and take action:

...to understand and be able and willing to act on global social issues... (D1-3)

...a willingness to recognise and act to ameliorate negative impacts of one's own actions. (D1-4)

Only one of the NTFs mentioned taking action - and this was weakly expressed as a possibility:

'these might include a commitment to positive action...' (D1-9, emphasis added).

The other NTF responses were closer to those of the majority of students, suggesting a general sense of 'being' global and awareness of global communities:

'A global citizen is someone who strongly identifies themselves as a citizen of the world' (D1-6).

Much like the students, there was a tacit suggestion of the potential to act, but the transactional value of awareness was much more apparent.

Another key distinction between the two groups of respondents was that the loC experts all expressed concern for using the term at all, or indeed any terms in several cases, noting instead the difficulty of identifying an agreed definition. None of the NTFs suggested that the term was problematic, or that it might overlap with others. This again mirrored the responses of the students. No students in our survey questioned the validity of a difference between GC and CCC.

Conversely, the responses to the questions on Cross-cultural competency were more consistent between all experts and converged on CCC as a matter of awareness, understanding and knowledge of other cultures, or the ability to learn these skills:

'The abilities to interact with others whose cultural norms and rituals may be different from one's own...' (D1-4)

'...the competence to understand culture across differences...' (D1-3) 
Final submitted version of paper subsequently published as: Cotton, D.R.E., Morrison, D., Magne, P., Payne, S. and Heffernan, T. (2018) Global Citizenship and Cross-cultural Competency: Student and expert understandings of internationalisation terminology. Journal of Studies in International Education.

All but one of the replies focused on working or living with other cultures, but only three tangentially referred to matters of social justice, equality or direct action:

'...to learn to understand other cultures to the point where they are able to work within and across a range of different intercultural situations.' (D1-5)

'The ability or willingness to work/study effectively with people of other cultures.' (D1-8)

'The skills and attributes required to study and work effectively in a multi-cultural environment.' (D1-9)

Like the students, the experts shared the view that CCC could be learned. Thus it may prove more amenable to inclusion as part of loC.

In the second round of our Delphi survey, we addressed some of the ambiguity identified, and asked about whether the terms used for loC mattered. Of the five overall responses (two loC, three NTF), four felt the choice of terms was very important. Each also noted the academic tendency towards overcomplication and a lack of focus on practical, consistent use of the terms:

... we have to make them concrete and understandable and applicable in practice. Many of the terms have a high level of abstraction and generalisation... (D2-3)

I think it is important both to pick a term/brand and spend a bit of time defining it. (D24)

I do not know if the terms are ambiguous, but most lecturers do not know the literature and interpret the terms as they see fit. (D2-2)

The only dissenting view, one of the loC experts, was that we should not use any terms at all, but rather embed loC throughout the curriculum of all subjects without mentioning it directly.

\section{Discussion}

The lack of clarity regarding the aims of loC is unlikely to be resolved until there is greater agreement on the terminology used to describe it. If a core aim is to develop a sense of personal agency amongst 
Final submitted version of paper subsequently published as: Cotton, D.R.E., Morrison, D., Magne, P., Payne, S. and Heffernan, T. (2018) Global Citizenship and Cross-cultural Competency: Student and expert understandings of internationalisation terminology. Journal of Studies in International Education.

students (as much of the literature indicates), then the choice of terminology may have a substantial pedagogic impact. Compared to the Internationalisation experts, students and pedagogic experts alike had little sense of Global Citizenship as contested, but it was widely understood in quite a passive sense - as something one has, rather than something one can learn or act upon. The prevailing literature, as well as the responses of the Internationalisation experts in our Delphi survey, regards GC as necessarily active and involving individual responsibility. Our results show that students do not see it this way at the beginning of their HE studies. The nearly complete lack of agency and responsibility in understandings of GC strongly undermines its presumed transformative power in the literature, though it may help explain the studies that failed to find evidence of positive student outcomes through GC education (Rhoads and Szelényi 2011; Jones and Killick 2013).

There is some indication in the data of 'rhetorical ambiguity' at play here: Stables and Scott (2002) (in the context of sustainable development) describe a term that is 'rhetorically constructed to appeal simultaneously to apparently opposed interest groups' (53), and that agreement on the importance of a term may mask substantial divergence in underlying beliefs. Perhaps this conceptual ambiguity is inevitable, given the complexity of IoC and the diverse range of ways that it might be embedded in different subjects. However, unlike the literature outlined earlier (e.g. Toh, 1996; Clifford and Montgomery, 2011), student responses provide little indication that they perceived GC as a 'transformative' agenda that will offer solutions to global problems. Evidently, it would be possible for students to develop a fuller understanding over their time at university; however, the similarity between their understandings and those of even expert teachers, suggests that lecturers may not be in a strong position to inculcate this more radical understanding. Recent research on staff understanding and engagement with loC (particularly global citizenship) notes the limited staff attention to diversity in the classroom and attributes this to a lack of inter-cultural experience and training (Kirk et al., 2018). This same research notes a lack of staff understanding of, and confidence with loC in general and GC in particular, supporting our perception that this concept can prove problematic in practice.

While the term cross-cultural competency was less widely known amongst students, it invoked a much more active understanding in terms of personal responsibility. In contrast to the literature which often utilised instrumental definitions (e.g. Early, 2002; Jones, 2013), these students showed considerable grasp of personal responsibility for positive international action, as well as a very high uniformity of definition across the subject areas. This finding reinforces the work of Odag et al. (2016) on intercultural 
Final submitted version of paper subsequently published as: Cotton, D.R.E., Morrison, D., Magne, P., Payne, S. and Heffernan, T. (2018) Global Citizenship and Cross-cultural Competency: Student and expert understandings of internationalisation terminology. Journal of Studies in International Education.

competence in suggesting that students' views are less instrumental than those in the literature, but in addition offers some cause for optimism that these views were widely held across a general sample of students - rather than simply those developed through a specific initiative.

Despite the uniformity of student responses in this study, their understandings of CCC were not shared by the pedagogic experts in our sample. This would suggest that, whilst CCC might be a clearer term to present to students, effort would need to be made first in developing staff understandings of an agential and broad-reaching definition which differs from that present in much of the current literature. This echoes Leask and Bridge's (2013) claim that 'many academic staff either are uncertain what internationalisation of the curriculum means or do not think it has anything to do with them' (80). In contrast to the debate about whether CCC attributes are intrinsic or can be taught (Leiba-O'Sullivan, 1999; Johnson et al., 2006; Caligiuri and Tarique, 2012), for our respondents this term was more explicitly linked with learning than GC - cross cultural competencies seemed to be perceived by students as skills which they do not necessarily have but which they might reasonably be expected to acquire over their time at university.

A final nuance which might have some bearing on appropriate pedagogies for loC was the way in which 'cultural awareness' was mentioned in different contexts. This term was relatively frequent in definitions of both CCC and GC, but often remained undefined or lacked additional terms to expand on it. These isolated statements left a sense of it being transactively sufficient to merely be aware of other cultures, agency was lacking. Conversely, where cultural awareness coincided with mention of inclusivity, equality, or even instrumental aims such as freedom of working, explicit mention of personal agency was often present as well. This suggests that a sense of agency coincides with students having a notion of underlying value or purpose for having cultural awareness, but that possessing cultural awareness itself is insufficient to promote the aims of loC. Thus it seems essential that pedagogies for loC should focus on contextualising the practical value (instrumental or social) of applying cultural awareness.

These findings also have implications for other education sectors. Since 2002, citizenship has been a statutory subject in the National Curriculum in secondary schools in England for 11-16 year olds, and elements of citizenship education appear across many school subjects. Both global citizenship and intercultural competence are often included within the training of teachers in varied international contexts (Bourn et al., 2017). However, our research raises interesting questions about how trainee or experienced teachers might understand these concepts and thus how well prepared they feel to teach 
Final submitted version of paper subsequently published as: Cotton, D.R.E., Morrison, D., Magne, P., Payne, S. and Heffernan, T. (2018) Global Citizenship and Cross-cultural Competency: Student and expert understandings of internationalisation terminology. Journal of Studies in International Education.

pupils about them. The fact that the concepts were less often considered to be contested by nonexperts might actually make them easier to incorporate into school teaching since concerns about inclusion of controversial issues are well documented (see Cotton, 2006). Understandings of GC and CCC by school teachers and pupils would provide an interesting topic for future research.

\section{Conclusions and recommendations}

In this paper, we have argued that two key concepts discussed in the literature, and often used to underpin loC in practice, are ambiguous both to students and to some academic staff. Our research suggests that there is considerable variation in interpretation of global citizenship and cross-cultural competency within and between different stakeholder groups. The understanding of 'agency' embedded within each of these terms differs considerably between the literature and our findings. (Broadly speaking, GC was seen by our respondents as instrumental, while the literature would suggest that it is agential and transformative, and CCC was seen as agential and transformative while the literature would suggest that it is instrumental). It is tempting to dismiss the use of either term, and instead ask students and staff to reflect on the role of their discipline and of themselves as active members of the international community. However, there are hints in our findings that use of crosscultural competency may be more effective in engaging students actively than the related term, global citizenship. Utilising a term that many students already associate with personal agency and responsibility, could go a long way towards embedding the deeper goal of actively responsible internationalisation into the curriculum.

Like a number of other critically important agendas, the complexity of internationalisation in the curriculum makes its embedding extremely challenging. This research highlights an important gap in the application of vocabulary that lies at the heart of loC. Students need clear and consistent direction through the terminology to understand the wider world and how they impact on it, particularly in the light of current global developments. A step change in pedagogies for internationalisation can only be achieved when there is more clarity over terms, enabling enactment of internationalisation to expand from the business disciplines into the wider HE context. In order to achieve the transformative aims of internationalisation (including promoting active responsibility for international engagement), critical reflection and nurturing of students' sense of agency will be central. Sterling (2001) argues that education can contribute to social transformation if it is informed by a paradigm characterized by 
Final submitted version of paper subsequently published as: Cotton, D.R.E., Morrison, D., Magne, P., Payne, S. and Heffernan, T. (2018) Global Citizenship and Cross-cultural Competency: Student and expert understandings of internationalisation terminology. Journal of Studies in International Education.

reflection, participation, empowerment and self-organization. Perhaps, like the field of Education for Sustainable Development (ESD), internationalisation has become increasingly beset by 'definition dementia' (Reid and Petocz, 2006) which limits the potential for successful communication. Gough (2002) comments: 'a field incapable of establishing agreed definitions of its most basic terminology seems unlikely to make any other sort of progress' (np). But perhaps what our research most clearly demonstrates is that an absolute definition of the terms may be less important than whether one term invokes the desired capacity to act in an international community. 
Final submitted version of paper subsequently published as: Cotton, D.R.E., Morrison, D., Magne, P., Payne, S. and Heffernan, T. (2018) Global Citizenship and Cross-cultural Competency: Student and expert understandings of internationalisation terminology. Journal of Studies in International Education.

\section{References}

Bates, R. (2012) Is Global Citizenship Possible, and Can International Schools Provide It? Journal of Research in International Education, 11(3), 262-274.

Beelen, J. and Jones, E. (2015) Redefining Internationalization at Home. The European Higher Education Area: Between Critical Reflection and Future Policies: Part 1, eds. Adrian Curaj, Liviu Matei, Remus Pricopie, Jamil Salmi, and Peter Scott.

Beelen, J., \& Leask, B. (2011). Internationalization at home on the move In Internationalisation of European Higher Education Handbook. Berlin: RaabeBird, A., Mendenhall, M., Stevens, M.J. and Oddou, G. (2010) Defining the content domain of intercultural competence for global leaders, Journal of Managerial Psychology, 25 (8), 810-828

Bourn, D., Hunt, F. and Bamber, P. (2017) A review of Education for Sustainable Development and Global Citizenship Education in Teacher Education. UNESCO Global Education Monitoring Report.

Bryman, A. (2008) Social Research Methods: Third Edition, Oxford University Press, Oxford

Caligiuri, P. and Tarique, I. (2012) Dynamic cross-cultural competencies and global leadership effectiveness. Journal of World Business, 47(4), 612-622

Clifford, V., and Montgomery, C. (2011) Moving Towards Internationalisation of the Curriculum for Global Citizenship in Higher Education. Oxford Centre for Staff and Learning Development.

Cotton, D.R.E. (2006) Teaching controversial environmental issues: neutrality and balance in the reality of the classroom. Educational Research 48 (2): 223-241

Crossman, J. E., \& Clarke, M. (2010). International experience and graduate employability. Higher Education, 59(5), 599-613.

Dei, G. (2008) Anti-racism education for global citizenship. In M. Peters, A. Britton and H. Blee (Eds), Global Citizenship Education: Philosophy, Theory and Pedagogy (Rotterdam, Sense), 477-490.

Early, C. (2002) Redefining Interactions across Cultures and Organizations: Moving Forward with Cultural Intelligence. Research in Organizational Behaviour. 24, 271-299

Gersten, M.C. (1990) Intercultural competence and expatriates, in International Journal of HRM, 1(3) 361-369

Gough, S. (2002) Right answers or wrong problems? Towards a theory of change for environmental learning. The Trumpeter: Journal of Ecosophy. 18 (1) Available online at: http://trumpeter.athabascau.ca/index.php/trumpet/article/view/122/132 
Final submitted version of paper subsequently published as: Cotton, D.R.E., Morrison, D., Magne, P., Payne, S. and Heffernan, T. (2018) Global Citizenship and Cross-cultural Competency: Student and expert understandings of internationalisation terminology. Journal of Studies in International Education.

Green, R.A. (2014) The Delphi Technique in Educational Research. Sage Open Monographs. 4 (2) Available online at: http://journals.sagepub.com/doi/abs/10.1177/2158244014529773

Hamdon, E. and Shelane J. (2009) Global Citizenship Education Policy Issues. Alberta: University of Alberta International and Faculty of Education.

Hammersley, M. (1998), Reading Ethnographic Research: A Critical Guide, Longman, London.

Hanson, L. (2010) Global Citizenship, Global Health, and the Internationalization of Curriculum: A Study of Transformative Potential. Journal of Studies in International Education 14(1), 70-88.

Hunter, B., White, G.P. and Godbey, G.C. (2006) What Does It Mean to Be Globally Competent? Journal of Studies in International Education 10 (3): 267-285llieva, J., Baron, S. and Healey, N. (2002) Online Surveys in marketing research: Pros and cons. International Journal of Market Research, 44(3), 361-376 Johnson, J.P., Lenartowicz, T. and Apud, S. (2006) Cross-Cultural Competence in International Business: Toward a Definition and a Model. Journal of International Business Studies 37(4), 525-43.

Jones, E. and de Wit, H. (2012) Globalization of Internationalization: Thematic and Regional Reflections on a Traditional Concept. AUDEM: The International Journal of Higher Education and Democracy, 3(1), 35-54.

Jones, E., and Killick, D. (2013) Graduate Attributes and the Internationalized Curriculum: Embedding a Global Outlook in Disciplinary Learning Outcomes. Journal of Studies in International Education, 17(2), 165-182.

Jones, G. (2013) Afterword: Rates of Exchange: Neoliberalism and the Value of Higher Education. International Studies in Sociology of Education, 23(3), 73-80.

Killick, D. (2012) Seeing Ourselves-in-the-World: Developing Global Citizenship through International Mobility and Campus Community. Journal of Studies in International Education 16(4), 372-89.

Kirk, S.H., Newstead, C., Gann, R. and Rounsaville, C. (2018). Empowerment and ownership in effective internationalisation of the higher education curriculum. Higher Education (Early edition available online at: https://link.springer.com/article/10.1007/s10734-018-0246-1)

Knight, J. (2006). Internationalization of higher education: New directions, new challenges. Paris: IAU.

Leask, B. (2015) Internationalizing the curriculum. London: Routledge.

Leask, B. \& Bridge, C. (2013) Comparing internationalisation of the curriculum in action across disciplines: theoretical and practical perspectives, Compare: A Journal of Comparative and International Education, 43:1, 79-101

Leiba-O'Sullivan, S. (1999) The Distinctions between Stable and Dynamic Cross-cultural Competencies: Implications for Expatriate Trainability. Journal of International Business Studies, 30(4), 709-725

Lilley, K., Barker, M. and Harris, N. (2014) Exploring the Process of Global Citizen Learning and the Student Mind-Set. Journal of Studies in International Education. 19(3), 225-245. 
Final submitted version of paper subsequently published as: Cotton, D.R.E., Morrison, D., Magne, P., Payne, S. and Heffernan, T. (2018) Global Citizenship and Cross-cultural Competency: Student and expert understandings of internationalisation terminology. Journal of Studies in International Education.

Morais, D.B. and Ogden, A.C. (2011) Initial Development and Validation of the Global Citizenship Scale. Journal of Studies in International Education. 15(5), 445-466.

Odağ, Ö., Wallin, H.R. and Kedzior, K.K. (2016) Definition of Intercultural Competence According to Undergraduate Students at an International University in Germany. Journal of Studies in International Education. 20(2), 118-139.

OXFAM (2017) What is Global Citizenship?, http://www.oxfam.org.uk/education/globalcitizenship/what-is-global-citizenship (accessed 2/3/18)

Oxley, L. and Morris, P. (2013) Global Citizenship: A Typology for Distinguishing its Multiple Conceptions, British Journal of Educational Studies, 61(3), 301-325

Pashby, K. (2011) Cultivating Global Citizens: Planting New Seeds or Pruning the Perennials? Looking for the Citizen-Subject in Global Citizenship Education Theory. Globalisation, Societies and Education 9(3-4), 427-442.

Reid, A. and Petocz, P. (2006) University lecturers' understanding of sustainability, Higher Education. 51, 105-23.

Rhoads, R. and Szelenyi, K. (2011) Global Citizenship and the University: Advancing social life and relations in an interdependent world. Stanford, Stanford University Press.

Shultz, L. (2007) Educating for global Citizenship: Conflicting Agendas and Understandings. Alberta Journal of Educational Research, 53(3), 248-258

Silverman, D. (2005) Doing Qualitative Research, 2nd ed, Sage, London.

Stables, A. and Scott, W. (2002), The quest for holism in education for sustainable development, Environmental Education Research. 8 (1), 53-60.

Sterling, S. 2001. Sustainable education: Re-visioning learning and change. Totnes: Green Books.

Toh, S. (1996) Partnerships as solidarity: Crossing North-South boundaries. Alberta Journal of Educational Research, 42, 178-191.

UNESCO (2015) Global Citizenship Education. Paris: UNESCO.

Wang, X. (2013) Cultivating Cosmopolitan Citizens: On Chinese citizenship education in the era of globalisation in Proceedings of Global Citizenship Curriculum in Higher Education: Evolving Policy and Practice and a Future Research Agenda, December, Bath Spa University, Hong Kong 
Final submitted version of paper subsequently published as: Cotton, D.R.E., Morrison, D., Magne, P., Payne, S. and Heffernan, T. (2018) Global Citizenship and Cross-cultural Competency: Student and expert understandings of internationalisation terminology. Journal of Studies in International Education.

Table 1: Subject background of participants

\begin{tabular}{|l|l|}
\hline Subject (discipline) & Faculty \\
\hline Primary Education (Education) & Arts \& Humanities \\
\hline English Literature & Arts \& Humanities \\
\hline Social Work & Health \& Human Sciences \\
\hline Chemistry & Science \& Engineering \\
\hline Maths & Science \& Engineering \\
\hline Biology & Science \& Engineering \\
\hline Software Development (Computing) & Science \& Engineering \\
\hline Tourism \& Hospitality (Tourism) & Business \\
\hline Marketing & Business \\
\hline
\end{tabular}


Final submitted version of paper subsequently published as: Cotton, D.R.E., Morrison, D., Magne, P., Payne, S. and Heffernan, T. (2018) Global Citizenship and Cross-cultural Competency: Student and expert understandings of internationalisation terminology. Journal of Studies in International Education.

Table 2: Response rates and demographic data

\begin{tabular}{|c|c|c|c|c|c|}
\hline & $\begin{array}{c}\text { Total } \\
\text { Responses }\end{array}$ & Female & Male & Age (avg.) & Response Rate \\
\hline Marketing & 45 & $45 \%$ & $55 \%$ & 19.1 & $73.8 \%$ \\
\hline Tourism & 35 & $77 \%$ & $23 \%$ & 19 & $71.4 \%$ \\
\hline Social Work & 24 & $87 \%$ & $13 \%$ & 27.9 & $42.1 \%$ \\
\hline Education & 124 & $73 \%$ & $27 \%$ & 19.9 & $79.5 \%$ \\
\hline English & 70 & $75 \%$ & $23 \%$ & 19.5 & $75.3 \%$ \\
\hline Biology & 77 & $59 \%$ & $41 \%$ & 21.1 & $45.6 \%$ \\
\hline Chemistry & 38 & $39 \%$ & $61 \%$ & 19.6 & $64.4 \%$ \\
\hline Computing & 30 & $0 \%$ & $100 \%$ & 19.8 & $76.9 \%$ \\
\hline Maths & 51 & $29 \%$ & $71 \%$ & 19.9 & $67.1 \%$ \\
\hline Total & 494 & $57 \%$ & $41 \%$ & 20.6 & $65 \%$ \\
\hline
\end{tabular}


Final submitted version of paper subsequently published as: Cotton, D.R.E., Morrison, D., Magne, P., Payne, S. and Heffernan, T. (2018) Global Citizenship and Cross-cultural Competency: Student and expert understandings of internationalisation terminology. Journal of Studies in International Education.

Table 3: Student understandings of Global Citizenship

\begin{tabular}{|l|c|c|}
\hline \multicolumn{1}{|c|}{ Global Citizenship } & N & $\begin{array}{c}\text { Percent } \\
\text { of } \\
\text { Cases }\end{array}$ \\
\hline One World/Global Community & 136 & $49.1 \%$ \\
\hline Agency/Responsibility (inactive type) & 53 & $19.2 \%$ \\
\hline Cultural Awareness and Understanding & 52 & $18.8 \%$ \\
\hline Agency/Responsibility (active type) & 33 & $11.9 \%$ \\
\hline No Borders/Free Travel & 30 & $10.9 \%$ \\
\hline Mobility and Communication Specifically for & 28 & $10.0 \%$ \\
\hline Work/Subject & 16 & $5.8 \%$ \\
\hline Having/Enacting a Positive Disposition to Others & 14 & $5.1 \%$ \\
\hline Communication & 13 & $4.6 \%$ \\
\hline World Relations(hips) & 12 & $4.3 \%$ \\
\hline Inclusivity & 11 & $4.0 \%$ \\
\hline Social/Cultural Equality & 9 & $3.3 \%$ \\
\hline Being Accepted by Others & 8 & $2.9 \%$ \\
\hline Helping Cultures/World & 6 & $2.2 \%$ \\
\hline Impact on World/Cultures & 6 & $2.2 \%$ \\
\hline Having Dual Citizenship & 3 & $1.8 \%$ \\
\hline Living Abroad & 3 & $1.5 \%$ \\
\hline Shared Learning & 3 & $1.2 \%$ \\
\hline Cultural Integration & $1.2 \%$ \\
\hline Agency/Responsibility (self only) & $1.0 \%$ \\
\hline Internationalisation of Curriculum & 3 & $1.0 \%$ \\
\hline Cultural Adaptability & $3 \%$ \\
\hline Negative View & 3 & \\
\hline Fame & 3 & $1.0 \%$ \\
\hline & 3 & 3 \\
\hline
\end{tabular}


Final submitted version of paper subsequently published as: Cotton, D.R.E., Morrison, D., Magne, P., Payne, S. and Heffernan, T. (2018) Global Citizenship and Cross-cultural Competency: Student and expert understandings of internationalisation terminology. Journal of Studies in International Education.

Table 4: Student Understandings of cross-cultural competency

\begin{tabular}{|l|c|c|}
\hline \multicolumn{1}{|c|}{ Cross-Cultural Competency } & N & $\begin{array}{c}\text { Percent } \\
\text { of } \\
\text { Cases }\end{array}$ \\
\hline Cultural Awareness and Understanding & 167 & $56.4 \%$ \\
\hline Agency/Responsibility (inactive type) & 134 & $45.3 \%$ \\
\hline Agency/Responsibility (active type) & 101 & $34.1 \%$ \\
\hline Having/Enacting a Positive Disposition to Others & 48 & $16.3 \%$ \\
\hline $\begin{array}{l}\text { Mobility and Communication Specifically for } \\
\text { Work/Subject }\end{array}$ & 35 & $11.9 \%$ \\
\hline Cultural Adaptability & 20 & $6.7 \%$ \\
\hline Inclusivity & 19 & $6.3 \%$ \\
\hline Internationalisation of Curriculum & 16 & $5.2 \%$ \\
\hline Shared Learning & 13 & $4.3 \%$ \\
\hline One World/Global Community & 13 & $4.3 \%$ \\
\hline Communication & 12 & $4.2 \%$ \\
\hline Social/Cultural Equality & 11 & $3.7 \%$ \\
\hline Unclear Meaning/No Category & 8 & $2.9 \%$ \\
\hline Political Correctness & 7 & $2.4 \%$ \\
\hline Cultural Integration & 6 & $2.2 \%$ \\
\hline Competition between Cultures & 6 & $2.1 \%$ \\
\hline Negative View & 5 & $1.7 \%$ \\
\hline World Relations(hips) & 5 & $1.7 \%$ \\
\hline Impact on World/Cultures & 4 & $1.3 \%$ \\
\hline Comparing Cultures & 3 & $1.0 \%$ \\
\hline Being Accepted by Others & 3 & $.9 \%$ \\
\hline Living Abroad & 2 & $.7 \%$ \\
\hline No Borders/Free Travel & 1 & $.4 \%$ \\
\hline Agency/Responsibility (self only) & 1 & $.3 \%$ \\
\hline Having Dual Citizenship & 641 & $216.5 \%$ \\
\hline & & \\
\hline
\end{tabular}

